\title{
TIEMPO PARA HABLAR Y TIEMPO PARA CALLAR: USO Y FUNCIÓN DEL SILENCIO EN UN AUTO RELIGIOSO DE FINES DEL XVI'
}

\author{
Rosa Durá Celma \\ Universitat de València
}

\begin{abstract}
RESUMEN: En este artículo nos proponemos una primera aproximación a un auto religioso inédito de fines del siglo XVI titulado Auto de la cena a lo divino, tomando como eje articulatorio del mismo la estrategia comunicativa que el anónimo dramaturgo lleva a cabo con la noción de silencio. En la primera parte analizaremos ampliamente el modo en que el autor se sirve de la ausencia de palabras para crear una atmósfera ritual y celebrativa que vincula esta pieza dramática con la liturgia. A continuación subrayaremos algunas fórmulas teatrales inherentes al lenguaje teatral relacionadas con el silencio que se descubren ineficaces en cuanto a su función primordial de generar tensión dramática, pero sí consiguen establecer cierta complicidad entre la acción y el virtual público de la representación.
\end{abstract}

PALABRAS CLAVE: Teatro religioso, silencio funcional, complicidad, estrategias de comunicación teatral, Contrarreforma, manuscrito.

\section{TIME TO TALK AND TIME TO KEEP QUIET: USE AND FUNCTION OF SILENCE IN A RELIGIOUS PLAY OF LATE $1^{\text {TH }}$ CENTURY}

\begin{abstract}
This paper proposes a first approach to a late 16th century unpublished religious play entitled Auto de la cena a lo divino. Silence as a communication strategy used by the anonymous author is the focus of this research. The first part analyzes how the author uses the lack of words in order to create a ritual and celebratory atmosphere which links this play with the liturgy. The second
\end{abstract}

1. Mi trabajo se beneficia de mi vinculación a los proyectos de investigación financiados por el MICINN con los números de referencia FFI2008-00813, CDS2009-00033 y FFI2011-23549. 
part outlines some general theatrical strategies concerning silence, which are proved to be inefficient as far as dramatic tension is concerned. Nevertheless, they do achieve complicity between action and virtual audience.

KEYWORDS: Religious theatre, functional silence, complicity, theatrical communication strategies, Counter-Reformation, Manuscript.

Manejar el silencio es más dificil que manejar la palabra

Georges Clemenceau

\section{Introducción}

En el principio fue el $\log o s,{ }^{2}$ el logos entendido aquí como verbo, como palabra, discurso; pero un discurso no solo está compuesto por una cadena en la que los significantes se combinan formando el sentido del texto, sino también por silencios. Tan importantes son las palabras como las pausas que las separan, de ahí que podamos decir que el silencio está dentro del lenguaje y, al mismo tiempo, en sus fronteras.

A partir de este supuesto y de la admisión del concepto de silencio en el marco de la literatura religiosa como "la otra cara de la palabra, la cara oculta del rostro de Dios" (Trebolle 2007: 227) es que me propongo en el presente trabajo un análisis del empleo y función que tiene el silencio en el espacio dramático de un auto religioso de fines del siglo XVI que toma como eje temático la Última Cena de Cristo con los apóstoles. Por un lado, centraré mi atención en el modo en que el anónimo dramaturgo recurre al silencio como procedimiento que le permite crear una situación extremadamente ritualizada y solemne que, valga decir, le viene exigida por los dos motivos cristianos que decide dramatizar: a saber, la institución de la Eucaristía y la ceremonia del lavatorio de pies. Por otro lado, analizaré el valor del silencio como estrategia generadora de una complicidad entre el personaje de Cristo y el público que tiene como telón de fondo el inminente descubrimiento de la traición de Judas.

El único testimonio hasta ahora conocido del Auto de la cena a lo divino ocupa el decimoquinto lugar en un códice facticio de 346 folios (ff. 250r-255v) con encuadernación antigua en pergamino, conservado en la actualidad en la Biblioteca

2. Así comienza el Evangelio de San Juan 1:1. La semántica del término logos se separó en latín en un primer término relacionado con el verbo decir-verbum-, y un segundo término relacionado con el verbo pensar -ratio-. 
Nacional de España (Ms.14.767). Los veintiún cuadernillos que conforman este manuscrito pertenecieron a la importante colección teatral de Diego Sarmiento de Acuña (1567-1626), conde de Gondomar, ${ }^{3}$ según descubrió el investigador responsable de la catalogación del conjunto de la colección, Stefano Arata (1996). ${ }^{4}$

No puedo detenerme en las particularidades codicológicas del manuscrito, no obstante sí anotaré que, en general, se trata de una copia bastante cuidada en la que se aprecia al menos la mano de tres copistas distintos (Puede verse la portada de la comedia en la imagen 1$) .5$

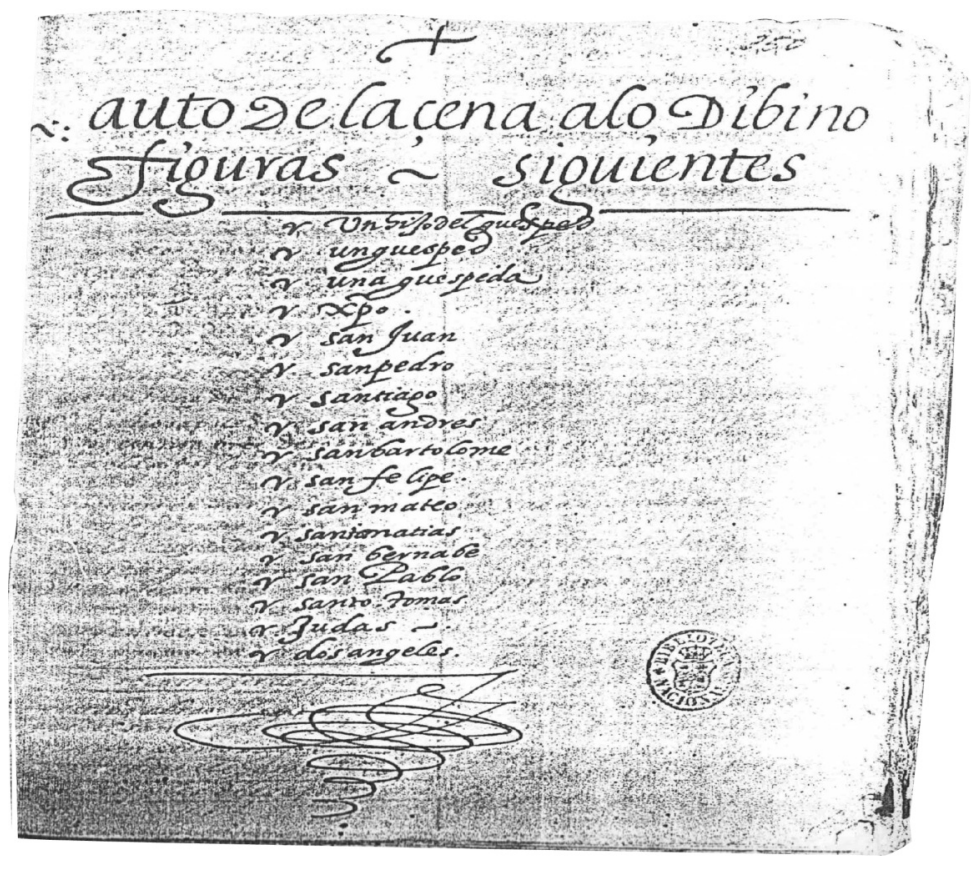

Portada del Auto de la cena a lo divino

(Madrid, Biblioteca Nacional de España, Ms. 14.767, f. 250r.)

3. En relación a la figura de este importante bibliófilo, véase Carmen Manso Porto (1996).

4. Aunque este manuscrito no ha sido estudiado globalmente, algunas de sus piezas han suscitado la atención de la crítica. En este sentido véanse los trabajos de Josefa Badía Herrera (2009a), (2009b), (2010), (2012); Teresa Ferrer Valls (2012); Natalia Fernández Rodríguez (2010); Mercedes de los Reyes Peña (2003).

5. Remito aquí al ya mencionado estudio de Stefano Arata (1996), así como al trabajo de Mercedes de los Reyes Peña (2003: 745-64). 
Asimismo, y aunque no es lugar este para entrar por extenso en los aspectos formales y escenográficos que caracterizan la pieza, sí cabría exponer concisamente la conclusión a la que me ha llevado el análisis cuidadoso de los personajes, estructura, esquema métrico, técnica teatral y tema. En definitiva, se trata de un auto considerablemente primitivo que no excede los 700 versos y que presenta un esquema métrico prácticamente isométrico. ${ }^{6}$ Las características estudiadas permiten emparentar mucho más estrechamente este auto con las obras que conforman el Códice de autos viejos, cuya fecha de composición Mercedes de los Reyes fija entre 1550 y $1575,{ }^{7}$ que con los autos religiosos del Lope más maduro, de Valdivielso, de Mira de Amescua o de Tirso de Molina.

En el Auto de la cena a lo divino resulta palmario que lo que guía la pluma del dramaturgo es el propósito de exaltación de la figura de Cristo como maestro y redentor, así como un plan de acomodo de los textos fuente al programa ideológico postridentino. Esta última afirmación se sustenta principalmente en el acento puesto sobre el papel del sacramento de la Eucaristía como elemento esencial para la salvación del hombre (f. $255 \mathrm{r}^{\mathrm{a}}$ ), en la constatación de san Pedro como padre de la Iglesia (f. $253 r^{\text {b }}$ ), en las directas alusiones a la presencia real de Cristo en la sagrada forma (f. $254 v^{a}$ ) y al sacramento de la confesión (f. $254 v^{b}$ ). Todos estos temas y motivos pueden entenderse como una respuesta seriada a los postulados protestantes vigentes en el momento de composición de la obra puesto que, a decir de José Luis Sánchez Lora, el arte católico reforzó intensamente aquellas creencias que consideraban herejías (1988: 367).

El Auto de la cena a lo divino tiene como compañeras de manuscrito dos comedias mariológicas, diecisiete comedias hagiográficas que evidencian la importancia que las vidas de santos adquirieron en el periodo contrarreformista, y un segundo auto cristológico en el que se dramatizan varios milagros de Cristo y el conocido pasaje del sermón de la montaña. ${ }^{8}$

6. Del total de versos de la pieza el 98.4 por ciento son redondillas (158 estrofas) y el 1.6 por ciento lo constituyen quintillas (156 estrofas).

7. No obstante, como bien señala esta investigadora, algunas de ellas pueden ser incluso anteriores (1988: 218).

8. Los títulos de estas obras son los siguientes: Comedia del católico español: el emperador Teodosio, atribuida en el manuscrito a Ramón; Comedia de san Isidro labrador de Madrid y victoria de las Navas por el rey don Alfonso, atribuida a Lope de Vega; Comedia de la vida y buenas costumbres de Juan de Dios; Comedia de santa Catalina de Sena; Comedia del glorioso san Martín; Comedia a lo divino sobre la envidia de Lucifer de haberse Dios humanado; Comedia de la vida y muerte y milagros de san Antonio de Padua; Comedia de san Segundo, atribuida a Lope de Vega; Comedia de san 
La fecha de composición de todas estas obras debe fijarse, según el investigador italiano mencionado, en torno a las dos últimas décadas del siglo XVI, y a la luz del estado actual de mi investigación, puede decirse que si bien algunas de las obras que componen el manuscrito están más próximas a la fórmula dramática de la Comedia Nueva, otras, en cambio, todavía evidencian características que las relacionan más acertadamente con la tradición anterior, como por ejemplo la escasa variedad métrica que presentan algunas de ellas, la alta densidad de palabra o la división en cuatro actos.

Hechas ya algunas puntualizaciones que me han permitido contextualizar mínimamente el auto, y tras aportar algunos detalles constitutivos de este, las páginas que siguen tendrán como objeto analizar este texto dramático bajo el enfoque del uso de un recurso tan propio del lenguaje teatral como es el silencio.

\section{Silencio y devoción: teatralización del rito}

Como su mismo título anuncia, el argumento del Auto de la cena encuentra sus mejores pilares en los textos neotestamentarios, concretamente en los capítulos en los que Mateo (26: 17-29), Lucas (22: 7-23), Marcos (14: 12-25) y Juan (13: 1-30) testimonian la Última Cena de Cristo antes de la Pasión.

La acción que organiza el auto se desarrolla a partir de una macrosecuencia que escenifica amplificándolo muy brevemente un momento capital para la institución del sacramento de la Eucaristía, cuyo protagonismo en los autos religiosos iba a ser cada vez mayor como consecuencia de la clausura del Concilio de Trento (1563) al que, como es sabido, siguió un clima de exaltación religiosa que iba a tener un claro reflejo en todas las manifestaciones artísticas (Bouza Álvarez 1990: 32).

Apunta Flecniakoska que para que exista drama debe de haber necesariamente acción, y la acción implica movimiento escénico, tensión entre fuerzas antagónicas (1961: 313). La acción del Auto de la cena es mínima y cristaliza en cinco secuencias

\footnotetext{
Jacinto, atribuida a Remón; Comedia de la vida y martirio de santa Bárbara; Comedia de la conversión de la Magdalena; Comedia de la vida y muerte de Nuestra Señora; Auto de la conversión de santa Tais (pese a la denominación genérico, es una obra dividida en cuatro jornadas, característica esta que la acerca más a la comedia que al auto); Comedia de la vida y muerte del santo fray Diego; Auto del milagro que Cristo hizo en sanar un endemoniado, un ciego y otros enfermos; Comedia de la vida y muerte de san Agustín; Comedia de Nuestra Señora de Lapa y un milagro que hizo; Comedia de la escala de Jacob; Comedia de san Estacio y Comedia de la vida y muerte de san Jerónimo.
} 
que constituyen cada una de ellas lo que podemos llamar un núcleo temático, a excepción de la última cuya extensión permite organizarla en varios de ellos. En el primer núcleo (f. 251ra) un matrimonio formado por una pareja de huéspedes se encuentra en el exterior de su casa a la espera de Cristo y los apóstoles, ya que es en la humildad de su hogar donde se va a celebrar el banquete pascual. La función dramática de esta microsecuencia es la de informar sobre lo que en ese espacio va a tener lugar. En la segunda escena (ff. $251 \mathrm{r}^{\mathrm{b}}-251 \mathrm{v}^{\mathrm{a}}$ ) se produce la multitudinaria llegada de los asistentes al lugar de la celebración. En ella el dramaturgo recurre a la conocida parábola de la red que se encuentra en Mateo (13: 44-50) para formular dos ideas fundamentales para el postulado cristiano: que Dios incluye a todos en su plan de salvación y la importancia que en ese mar que es el amor de Cristo tiene la predicación, es decir, la red que reúne a todos en un cuerpo común. El encuentro entre la pareja de personajes genéricos y los histórico-bíblicos constituye una tercera escena (f. $251 v^{\mathrm{a}}$ ) en la que los personajes que representan al fiel cristiano, la familia de huéspedes, se echan literalmente a los pies de Cristo y le expresan su incondicional devoción. Todo este júbilo y fervor por la figura de Jesús se verá truncado en la cuarta escena (ff. $\left.251 v^{b}-252 r^{a}\right)$. Pese a su brevedad evoca narrativamente, mediante un diálogo entre Pedro y Juan, varios momentos en los que el Mesías vaticinó su muerte. Dado el conocimiento del tema, estos malos augurios no contribuyen en nada a la creación de una tensión dramática y, por otro lado, esa tensión es inherente a la misma doctrina de la salvación ya que es necesario que Cristo muera para redimir al hombre. Por último, la quinta y última escena, la más extensa del auto (ff. $252 \mathrm{r}^{\mathrm{a}}-255 \mathrm{v}^{\mathrm{a}}$ ), como he señalado, puede ser dividida en cinco segmentos en los que se dramatizan distintos motivos. Es precisamente en esta última parte en la que centro mi análisis puesto que es aquí donde el dramaturgo lleva a cabo una estrategia de tensión-distensión no referida a una concentración de contenido teológico seguida de un momento de pausa cómica que alivia la catequesis que es así como utiliza este concepto Fraçois Cazal (1993: 47-60), sino en relación a una alternancia de la palabra evangélica y doctrinal coexistentes con unos significativos y dilatados silencios que apuntan a una propuesta dramática dirigida a un público que no debía ser un mero espectador, sino que también debía participar del espectáculo en calidad de feligrés.

El auto no presenta licencia de representación y hasta donde he podido indagar no tenemos constancia documental de su puesta en escena, ${ }^{9}$ con lo que la

9. Búsqueda que hemos efectuado entre los cerca de 2600 registros correspondientes a unos 4000 títulos de piezas dramáticas que gestiona la base de datos CATCOM. Las comedias y sus representantes: base de datos de comedias mencionadas en la documentación teatral (1540-1700), proyecto en preparación dirigido por Teresa Ferrer Valls. 
virtualidad de la representación solo puede ser aprehendida atendiendo a la información que nos ofrece el texto dramático llevando a cabo un ejercicio de visualización.

Tras las primeras secuencias que sirven de preludio al grueso del auto, nos encontramos con un primer momento en el que el huésped y su mujer disponen la mesa con los dones para la cena:

$\begin{array}{ll}\text { CRISTO } & \text { Oh, amigo, en paz estéis. } \\ \text { HuÉSPED } & \text { Con vos viene, Señor, esa. } \\ & \text { Ya quiero poner la mesa } \\ & \text { para que luego os sentéis. } \\ & \text { Id por el cordero ya } \\ & \text { y procurá no tardaros. } \\ & \text { Bien podéis sentaros } \\ & \text { que todo ya a punto está. } \\ & \text { Escuchad, traed primero } \\ & \text { las servilletas y el pan. } \\ & \text { ¿Hay cuchillos? } \\ \text { MuJER } & \text { Aquí están. } \\ \text { HuÉSPED } & \text { No saquéis más de un salero. (f. } 252 \mathrm{r}^{\mathrm{a}} \text { ) }\end{array}$

Tal y como explican las instrucciones del Misal romano, al comienzo de la Liturgia Eucarística se llevan al altar los dones que se convertirán en el cuerpo y la sangre de Cristo. Entre las viandas que figuran en nuestro auto no falta el cordero sacrificial, el pan y la sal, elementos todos con una fuerte carga simbólica, y entre los que debía encontrarse también el vino que, pese a no ser mencionado en este momento, se aludirá a él poco después en una acotación (f. $\left.254 \mathrm{v}^{\mathrm{b}}\right)$. Este núcleo temático resulta complementario a otro en el que el silencio se adueña del pasaje y adquiere un papel fundamental. Me refiero al momento en que se escenifica la ceremonia del lavatorio de pies por parte de Cristo a todos y cada uno de los apóstoles. A pesar de que el auto sigue muy de cerca el texto bíblico, es una aportación original del dramaturgo el gesto de Jesús ayudando a poner la mesa para el banquete pascual (f. $252 \mathrm{r}^{\mathrm{b}}$ ), acto que viene a reforzar el sentido que el rito del lavatorio implica, esto es, la puesta en valor de la virtud cristiana de la humildad. ${ }^{10}$ Igual que ocurre en el desarrollo litúrgico en donde el silenció permite comprender el sentido hondo de los signos y símbolos que edifican el rito (Muñoz 2010:

10. El dramaturgo parece que sigue el orden de los sucesos tal y como lo relata Juan, pues en este último el rito del lavatorio se produce antes que el anuncio de la traición. Por otro lado, no todos los evangelistas explicitan que es Judas el traidor, tal es el caso de Marcos y Lucas, en cambio Mateo no deja lugar a duda. 
291), el autor del auto parece querer aprovechar la ausencia de palabras para desplazar la atención del público hacia el valor simbólico de los objetos y acciones que se están representando con el fin de crear un clima ceremonial, solemne.

Seguido del pasaje del lavatorio, acontece uno en el que Cristo reparte entre los apóstoles los alimentos, les sirve de copero y, transcurrido ese tiempo, incita a Judas a que tome de su plato (Mt. 26, 23; Lucas, 22, 21; Juan, 13, 26; Mc, 14, 20), gesto que lo delata como traidor de cara al público. ${ }^{11}$ Es en este momento en el que dramaturgo pasa de los Evangelios sinópticos al de san Juan (13:1-20), único que relata el lavatorio de pies, dando así un giro a la acción dramática colocándola en una dinámica poderosamente litúrgica en que palabra y silencio se suceden alternativamente. Una vez se han retirado de la mesa, Cristo, intensificando la atmósfera religiosa, se despoja de la túnica morada que lleva, se provee de una toalla y se dispone a llevar a cabo el rito ante el estupor de los apóstoles. La escena resulta morosa y reiterativa, tanto en lo que se refiere al movimiento escénico, como a las fórmulas empleadas: la petición de Cristo a un apóstol para que se deje lavar los pies; el asombro y reticencias de este, pues no concibe la humillación del hijo de Dios; la insistencia o persuasión de Cristo; y por último, la aceptación y el acto mismo del lavatorio. Este movimiento se repite, si seguimos el texto, en diez ocasiones, aunque en la virtual representación de este auto debían de escenificarse también los lavatorios de los dos apóstoles que restan, por lo que se deduce de las palabras de Jesús unos versos más adelante: "Ya no hay más qué hacer que eso / no queda más a quien lave / que harto gusto que se acabe / hazaña de tanto peso" (f. 254rb).

Algunas interacciones entre Cristo y los apóstoles en el transcurso de esta acción suceden en absoluto silencio -en tres ocasiones aparece en forma de acotación el movimiento escénico de Cristo que debe lavar a los apóstoles que no hablan (f. $\left.253 v^{\mathrm{a}}, 254 \mathrm{r}^{\mathrm{a}}\right)-$; otras interacciones, en cambio, como las de san Pedro y san Juan -más importantes simbólicamente, y por esa razón el dramaturgo las presenta en primer lugar y les dedica un mayor número de versos- introduce blancos en el fluir de la palabra bíblica.

A esta situación dramática sigue una larga tirada -la más extensa del auto, formada por 78 versos- en la que Cristo, como un sacerdote en el sermón, descifra el significado del lavatorio explicando el sentido de lo que el espectador acaba de presenciar:

11. El gesto de mojar en el plato con Jesús es el que apunta a Judas como traidor de Cristo. En la Última Cena, Jesús se refiere a Judas como traidor tras la pregunta de los apóstoles: "El que ha mojado conmigo la mano en el plato. Ese me entregará” (Mt 26: 23-24). 


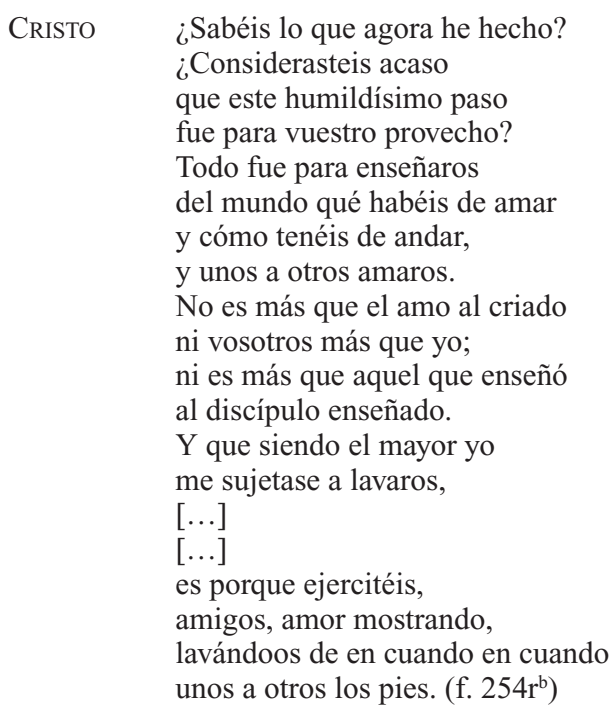

La exégesis bíblica asocia el lavatorio de pies con el sacramento de la confesión (Ratzinger 1990: 114-120) y, efectivamente, sentados de nuevo en la mesa, y tras anunciar Jesús su futura pasión y muerte (f. $254 \mathrm{r}^{\mathrm{b}}$ ), este introduce el tema eucarístico en unos términos precedidos por una interesante acotación que reza:

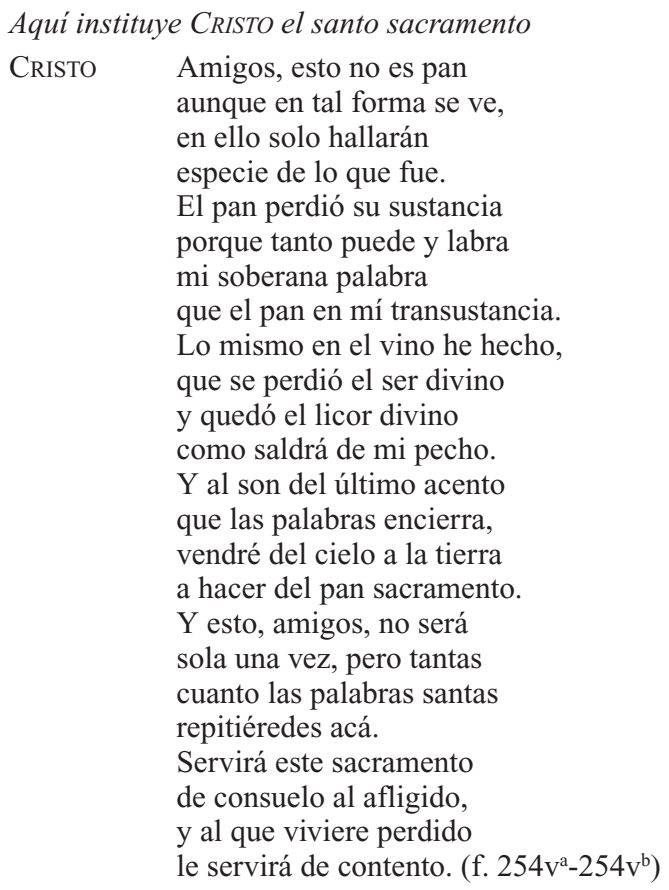


En el Auto de la cena a lo divino encontramos una proclamación de la doctrina católica más ortodoxa por medio de una exaltación de la Eucaristía que pasa por todos los puntos clave de esta: la institución del sacramento (f. $254 \mathrm{v}^{\mathrm{a}}$ ), la presencia real de Cristo en la Forma (f. $254 v^{\mathrm{a}}$ ) y la transubstanciación. Esta explicación sobre un punto cardinal del ideario contrarreformista incluye además una alusión a la trascendencia concedida en el programa cristiano al sacramento de la confesión (f. $254 \mathrm{v}^{\mathrm{b}}$ ), pues como puede verse tan solo acudiendo a los catecismos de la época, por ejemplo al de Ripalda, editado por Luis Resines en 1987, la confesión es una disposición previa a la comunión (1987: 347-48). Es necesario, pues, desde el punto de vista teológico que orienta nuestra pieza teatral, que Cristo lave los pies sucios del hombre para hacerlos dignos de su gloria y que este se entregue a él con el alma limpia.

El procedimiento del silencio tiene una sustancial importancia en los textos sagrados. Julio Trebolle, a cuyo artículo remitimos para una profundización del silencio en los textos bíblicos, observa que el mundo antiguo no conocía la plegaria silenciosa; únicamente la oración en voz alta. El silencio en la plegaria era motivo de toda clase de sospechas. Sólo la transcendentalización del concepto de divinidad operada en círculos platónicos y neoplatónicos condujo progresivamente a la idea de que el silencio podía constituir la forma más pura de culto religioso (2007: 231). En la esfera de las celebraciones litúrgicas, el silencio se concibe como el medio que permite escuchar la verdad de la palabra de Dios (Urdeix 2012: 65). Por otro lado, en las instrucciones del Misal romano (apartado de la Comunión, punto 84), puede leerse lo siguiente: "El sacerdote se prepara para recibir fructuosamente el cuerpo y la sangre de Cristo con una oración en secreto. Los fieles hacen lo mismo orando en silencio".

Reparemos ahora en la acotación que indica el movimiento escénico que sigue a la explicación sobre los dones del sacramento. Dice así: "Toma Cristo un panecito y hácele doce partes y le va dando a los apóstoles y luego de beber con un cáliz" (f. $254 \mathrm{v}^{\mathrm{b}}$ ). Aunque carezcamos de mayor indicación, es imposible pensar que esta acción no se desarrollase de forma ralentizada y en un riguroso silencio que reproduciría en las tablas, tanto el acto inaugural de Jesús en la Última Cena, como el gesto diario de la fracción del pan por parte del sacerdote en la misa.

Tras el acto de comunión el auto se precipita hacia su fin. Cristo anuncia que hay un traidor sentado a la mesa y denuncia su identidad. Judas sale rápidamente y entre lloros y lamentos los apóstoles se despiden de su maestro. El broche final lo pone el 
canto que inicia el salmo 112, ${ }^{12}$ el Laudate pueri dominum, el primero de los seis salmos que componen el Hallel, texto que los judíos empleaban en las celebraciones, en particular en la cena pascual. Volviendo al Misal romano. En el punto 86 se afirma que mientras se distribuye el Sacramento a los fieles, tiene lugar el canto de Comunión. En este mismo apartado se explicita también dos aspectos que nos interesa ahora subrayar: en primer lugar que, puesto que es posible cantar un himno después de la Comunión, el primer canto debe ser terminado oportunamente, con lo cual tras la Comunión tenía lugar un canto, igual que sucede en el Auto de la cena. En segundo lugar, se dice que entre las posibles composiciones musicales que se pueden ejecutar se encuentran los salmos, y que estos pueden ser interpretados bien por el coro solo, bien por el coro en conjunción con el pueblo, o bien un solo cantor con el pueblo (punto 87 del Misal). Por otro lado, conviene señalar que la salmodia debe ser concebida como "una escucha de la palabra [de Dios], tanto cuando los salmos son recitados o cantados por la comunidad, como cuando es un solista quien canta o recita un salmo concreto" (Cerezo 2010: 684).

La presencia de la música no es en absoluto una novedad en el teatro sacro, y así lo atestiguan colecciones de dramas religiosos anteriores y contemporáneas a esta obra como son las obras que forman el repertorio de las consuetas mallorquinas; dos de los tres misteris del Corpus valenciano; ${ }^{13}$ muchas de las piezas teatrales que figuran en el Códice de autos viejos y todos los dramas incluidos en el llamado Manuscrito de $1590 .{ }^{14}$ Atendiendo al lugar que el canto y la música ocupa en las obras religiosas mencionadas, y haciéndonos eco de la opinión de Bruce Wardropper cuando firma que "la participación popular en una función dramática [...] no es nada extraordinario en España" (1967: 86), sería plausible pensar, dadas las propiedades que presenta el auto, que el público que asistiese a la representación de esta obra estaría convocado a cantar a coro este salmo como colofón a la celebración, lo que acentuaría todavía más el carácter celebrativo y devocional del espectáculo.

Hasta aquí hemos visto lo que podemos llamar una manifestación total del silencio basada en el mutismo de los personajes en algunas secuencias, ahora me

12. El 112 según la numeración griega o latina, el 113, según la hebrea. Este salmo no figura en el texto, sino que se indica mediante la última acotación del auto.

13. El Misteri de san Christòfol y el Misteri de Adam y Eva. La primera obra citada fue publicada por Josep Romeu (1957: 32-45); la segunda fue publicada por Ferrán Huerta Viñas en Teatre biblic, (1976: 101-19).

14. Para más detalle sobre la importancia de la música en estas piezas dramáticas, véase Mercedes de los Reyes (1988: 1127-1228). 
detendré, mucho más brevemente, en los silencios parciales, es decir, aquellos que equivalen a un deseo de no decirlo todo, de no decir para todos, de los decires a medias, o incluso del callado decir del cuerpo.

\section{Falsa tensión y verdadera complicidad: el silencio como puntal}

Toda una serie de recursos propios del género teatral tales como la suspensión de información, las reticencias, la disimulación o la interrupción tienen lugar en esta pieza dramática en torno a la relación entre Cristo y Judas. Es necesario advertir que, ciertamente, en el Auto de la cena el conflicto dramático apenas existe, está prácticamente ausente en la construcción interna de los personajes y es mínimo en las interacciones que se establecen entre ellos. La única excepción la encontramos ligeramente pronunciada en los momentos en que, de forma más o menos explícita, el tema de la traición pasa a primer plano, y esta es una tensión que se observa ya en los textos bíblicos.

Como destaca con toda razón Marie-Françoise Déodat-Kessedjian, el aparte es, sin lugar a dudas, el recurso teatral por el que más se transparenta la escritura del silencio (1999: 62). Pese a que en la edición de textos teatrales en el periodo Barroco, no siempre los apartes eran señalados en las correspondientes acotaciones (Orozco 1983: 157) -menos todavía en periodos previos- no hay que pensar que no estén programados en las diferentes propuestas dramáticas, aunque lo estén de forma no señalada. En el auto que nos ocupa tenemos un claro ejemplo de un diálogo aparte entre Judas y Cristo en presencia del resto de personajes donde estos últimos permanecen ajenos a lo que aquellos se traen entre manos. Este recurso permite al espectador de la obra captar, no solo cierta actitud condescendiente e incluso irónica por parte de Jesús hacia Judas, sino también un atisbo de tensión interna en el personaje de Cristo, pues por un lado percibe su muerte como un acontecimiento ineludible sin el que la redención del hombre no sería posible y, por otro, expresa la imposibilidad de ablandar al que lo ha traicionado.

Las figuras de Pedro y Judas cobran especial relevancia en este auto: uno como cimiento de la Iglesia (f. 253rb), otro, el que ahora nos interesa, como pieza fundamental en el camino de salvación del hombre. Esta última idea es formulada por el personaje de Cristo en el único aparte que encontramos en el auto, y se produce en el momento en que Cristo se dirige a Judas en términos más que reticentes:

CRISTO ¡Oh, Judas, Judas hermano, ya os llega la tanda a vos! [Aparte] Acá entre solos los dos nos habremos mano a mano. 


$\begin{array}{ll} & \text { Estos pies tan buenos son } \\ & \text { que me huelgo yo de vellos, } \\ \text { porque Dios habrá por ellos } & \text { la general redención. } \\ & \text { Judas, ¿no somos amigos? } \\ \text { JUDAS } & \text { Sí señor, pues... ¿no lo veis? } \\ \text { CRISTO } \quad \text { ¡Hui, que en mis manos tenéis } \\ \text { dos bien contrarios testigos! } \\ \text { ¡Paso! ¡Tené! No echéis agua. } \\ \text { Aguardad, esperá un poco, } \\ \text { que aunque en el carbón yo toco, } \\ \text { estase muerta la fragua. (ff. } 253 \mathrm{v}^{\mathrm{a}}-253 \mathrm{v}^{\mathrm{b}} \text { ) }\end{array}$

Como se ha podido comprobar, esta tirada de versos y los que la siguen quedaría reducida al silencio dentro de la ficción dramática a efectos del resto de personajes, y así lo corrobora la acotación que figura poco después en la que leemos: "Aquí llega Cristo a los pies de Judas mucho" (f. 253v v).

La suspensión es también otro modo de operar con el silencio. En determinados momentos de la acción los personajes, no así el lector o espectador del auto, carece de la información necesaria para comprender la situación en la que está inmerso. Una muestra de ello, la más significativa, la encontramos en el momento en que Cristo invita a Judas a comer de su plato. Tras esa acción que señala a Iscariote como delator y que sería perfectamente interpretada por un público católico cuya vida estaba atravesada por la religión, Jesús interrumpe la cena, y durante un breve espacio de tiempo intensificado por un cambio de vestuario a vista del público y del que ya hemos hablado a propósito del movimiento ritual que procuraba a la obra, deja en suspenso la acción intensificando la curiosidad de san Pedro:

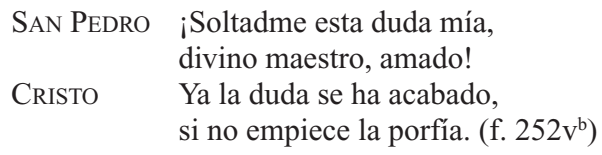

Más importante en lo que se refiere a la generación de tensión dramática, es la interrupción que se produce en el tramo final del auto. Cristo, tras administrar la Eucaristía, anuncia que entre ellos se encuentra el enemigo que lo ha vendido (f. $255 \mathrm{r}^{\mathrm{a}}$ ). El aplazamiento de la información que revelará la identidad del traidor da lugar a una serie de réplicas en las que los apóstoles se preguntan, siguiendo los textos evangélicos, quién será el culpado (f. $255 \mathrm{r}^{\mathrm{r}}$ ). Muy poco después Cristo resuelve la incógnita pronunciando la conocida sentencia: "De los que a la mesa están / a quien diere yo un bocado" (f. $255 \mathrm{r}^{\mathrm{a}}$ ), e inmediatamente después le ofrece el bocado a Judas, propiciando la precipitada salida de este. 
El término disimulación encierra en su definición la idea de encubrimiento, bien de unos sentimientos, bien de una identidad, bien de una intención. En el disimulo entra en juego un velo construido con palabras y gestos destinados a silenciar una verdad. Las palabras que Cristo dirige a Judas están continuamente cruzadas por una intención sesgada que oculta el hecho transparente para el espectador de que Jesús sabe que Judas es el delator. Así no duda en preguntarle: "Judas, ¿no somos amigos?” (f. $253 \mathrm{v}^{\mathrm{a}}$ ) -palabras alusivas que callan más de lo que dicen-, a lo que este siguiendo la tónica del disimulo le responde: “Sí, señor, pues... ¿no lo veis?” (f. 253va).

Para completar la ejemplificación, sirvan de botón de muestra estos versos en los que Cristo, cuando se dispone a besar los pies de Judas, siente en sus manos el temblor de su delator, lo que constituye un inequívoco y silencioso signo corporal que certifica su culpabilidad y temor: ${ }^{15}$

CRISTO $\quad$ Pies, sosegaos, no tembléis,
que el que os mueve no es traidor
para que con tal temblor
entre mis manos estéis.
Y aunque contra mí lo fuera,
pues que con su bien le ruego,
perdonaráselo luego
como el perdón me pidiera. (f. $\left.254 \mathrm{v}^{\mathrm{b}}\right)$

Como antesala a las conclusiones de este trabajo, reparemos muy brevemente en la siguiente afirmación de Anne Ubersfeld: "C $C$ 'ést à l'interieur de l'analyse du discours au théâtre qu'il nous sera possible de préciser ce que représente pour le discours théâtral la notion de personnage, et réciproquement comment le personnage est déterminé par son discours" (1978: 148). Teniendo muy presente la idea planteada por esta estudiosa del teatro acerca de lo indispensable que resulta atender al nexo entre un personaje y su discurso, me gustaría hacer un último apunte sobre la utilización del silencio en este auto. Para ello necesito remitir al porcentaje de versos que profieren los personajes de la obra. De las dieciocho figuras que el dramaturgo convoca en escena, siete son comparsas mudos. Cristo, como indiscutible protagonista del auto, pronuncia 323 versos, lo que supone el cincuenta por ciento del total; san Pedro, con un gran peso en la obra, dice 117 versos, el dieciocho por ciento; y casi la mitad de este son los versos que pronuncia san Juan (66 versos, el 10 por ciento). Detrás de ellos ya vienen figuras como el Huésped (51 versos, 8 por ciento), Felipe (13 versos), Bartolomé ( 24 versos), la mujer del hués-

15. Como bien dice Déodat-Kessedjian el cuerpo participa del lenguaje sin palabras (1999: 49). 
ped (18 versos), Santiago (11 versos.), el hijo del huésped y Mateo (ambos 6 versos). Ante estos datos llama poderosamente la atención, sobre todo teniendo en cuenta que Judas es una pieza angular de la trama y que Cristo dedica a su persona, bien directa o indirectamente, un total de setenta y un versos, que el dramaturgo $c a$ racterice al traidor con un discurso prácticamente mudo, pues en el desarrollo del auto tan solo 5 versos son pronunciados por él. Así las cosas podemos apreciar la decisión dramática del autor de privar del don de la palabra al enemigo de Cristo, al traidor y al cobarde, sustrayéndole toda posibilidad de protagonismo.

Llegados a este punto recapitulemos. El silencio dramático asume en este auto religioso un doble papel funcional. Por un lado, favorece la creación de una atmósfera ritual y celebrativa; por otro, y entendiéndolo en un sentido más amplio, es constitutivo de una serie de recursos teatrales que, como hemos ido viendo, retrasan la acción, crean espera o participan de una caracterización.

Por lo que se refiere a la primera función, hay que atender a varios aspectos. El primero de ellos es un esquema dramático que descansa fundamentalmente en la repetición de movimientos escénicos, de gestos y de fórmulas verbales. El segundo, lo constituye el efecto simbólico y litúrgico del cambio de ropa de Jesús - de la túnica morada a la blanca-, la presencia del pan y del cáliz en escena, así como los simulacros del lavatorio y de la partición de la Sagrada Forma y su administración a todos los apóstoles. Finalmente, el canto de un salmo dedicado a la grandeza de Dios que sirve de colofón celebrativo. Todos estos ingredientes tienen cabida en un breve auto compuesto por 634 versos cuya baja densidad de palabra - una media de cuatro versos por intervención- nos podría hacer pensar en una puesta en escena relativamente ágil y dinámica que no requeriría un tiempo de representación excesivamente dilatado. Sin embargo, el marcado movimiento ritualizado que lo articula, muchas veces acompañado de elocuentes silencios que crean esa atmósfera solemne tan apropiada para la espiritualidad, dilata esa suerte de sermón dogmático que es el auto - pues dogmas son la Eucaristía, la confesión o la institución de Pedro como cimiento del edificio de la Iglesia (f. $253 \mathrm{r}^{\mathrm{b}}$ )- y sugiere un tiempo de representación mucho más extenso a partir del cual puede deducirse la deliberada morosidad que el dramaturgo quiere imprimir a la pieza.

En cuanto a la segunda función del silencio. Signos suyos como la suspensión, la interrupción o la disimulación atañen o pueden atañer tanto a la trama y a los personajes de la obra como al público receptor. En este caso, no veo aventurado afirmar que todos estos recursos teatrales afines al silencio -insistimos- lejos de contribuir a la tensión dramática, y por la misma naturaleza de los acontecimien- 
tos que se escenifican, a lo que apuntan es a buscar cierta complicidad con el espectador. Las medias palabras de Cristo, la suspensión de la acción o el doblez de algunas réplicas no exigen un desciframiento o interpretación por parte del receptor de la obra, puesto conoce sobradamente el desenlace. Por ese motivo, en esta pieza dramática, el placer del reconocimiento y la compartición de creencias comunes prevalece sobre el placer de la sorpresa y la admiración así como sobre el valor dramático y estético.

El Auto de la cena a lo divino, un auto en el que el silencio no para de hablar, se encuentra a medio camino entre los textos dramáticos religiosos de la primera mitad del Quinientos - piezas más litúrgicas y morales alentadas por el impulso de la Reforma-y los autos más rigurosamente dogmáticos afines a los intereses de la Contrarreforma (Menéndez Peláez 2005: 52). El dramaturgo hace hincapié tanto en el modelo que ofrece la vida de Jesús basado fundamentalmente en la humildad, el sacrificio y el amor al prójimo como en la exposición de la enseñanza eucarística que incluye una alusión tangencial a las bondades de la confesión. El auto responde por tanto a un propósito didáctico, efectivamente, pero hay que aclarar que la articulación conceptual que despliega este auto religioso es sencilla y está escasamente desarrollada. Asimismo vislumbramos en el autor de esta obra la clara voluntad de crear un espacio dramático desde el que conmemorar un acontecimiento cardinal para la Iglesia contrarreformista como es la institución del sacramento de la Eucaristía, sirviéndose para ello de un procedimiento tan afín a la liturgia como el silencio. Los momentos de silencio en las celebraciones litúrgicas, afirma Mercedes de los Reyes, tienen una clara función en el marco de la ceremonia: poner de relieve la dimensión contemplativa de las celebraciones (1988: 679).

Volviendo al universo dramático. Si entendemos con Déodat-Kessedjian que un silencio que permite otro tipo de comunicación es un silencio funcional (1999: 18), no cabe duda de que en este auto el dramaturgo ha convertido dicha noción en una eficaz herramienta que le ha permitido armar una obra, que si bien desde el punto de vista dramático resulta todavía bastante primitiva, sí evidencia unas fronteras difusas entre el universo del teatro y el de la liturgia. Podemos concluir, pues, que el dramaturgo integra lo celebrativo y devocional con la doctrina y las enseñanzas evangélicas. Empleando el molde teatral llega a la misma meta que persigue toda liturgia que se realiza por medio de signos sensibles: alimentar y robustecer la fe (Misal romano, punto 20).

Dice George Steiner que "el silencio tiene un decir distinto del ordinario pero de todos modos se trata de un decir significativo" (2003: 71). Precisamente, y si la 
palabra en este auto está al servicio de una instrucción de ideas fácilmente comprensibles por parte de las masas menos instruidas que busca afianzar sus creencias, existe también, hermana en intención, una retórica del silencio que induce a crear, ayudada por la repetición que anida en el rito, un estado mental, o si se quiere espiritual, que favorece la participación emotiva del público, que comulga con lo sagrado y contribuye a la edificación y al consuelo del espectador cristiano desde el espacio privilegiado de comunicación que le ofrece el teatro.

\section{Bibliografía}

Auto de la cena a lo divino (Ms. 14.767), Biblioteca Nacional de Madrid.

ARATA, S. (1996). "Teatro y coleccionismo teatral a fines del siglo XVI: el Conde de Gondomar y Lope de Vega". Anuario Lope de Vega 2: 7-24.

BADÍA HERRERA, J. (2009a). "Los papeles de actor sueltos de la Santa y buenas costumbres de Juan de Dios: de las tablas al texto de lectura privada", Lemir 13: 281-334.

BADÍA HERRERA, J. (2010). "El programa contrarreformista en una comedia anónima de fines del XVI: La vida y muerte del santo fray Diego". Voz y letra 21 (2): 37-59.

BADÍA HERRERA, J. (2012) "Las pecadoras penitentes en los dramas religiosos de la colección teatral del conde de Gondomar" en La Biblia en el teatro español. (Ed. F. Domínguez Matito y J. A. Martínez Berbel). Vigo, Pontevedra: Academia del Hispanismo; San Millán de la Cogolla, La Rioja: Fundación San Millán de la Cogolla: 675-685.

BOUZA ÁLVARES, J. L. (1990). Religiosidad contrarreformista y cultura simbólica del Barroco. Madrid: CSIC.

CAZAL, F. (1993). "Tensión y distensión en el teatro religioso: la Farsa Theologal de Diego Sánchez de Bádajoz”. Criticón 58: 47-60.

CEREZO, M. (2010). "El silencio en la liturgia monástica”. Liturgia y espiritualidad 41: 679-685.

DÉODAT-KESSEDJIAN, M. F. (1999). El silencio en el teatro de Calderón de la Barca. Madrid: Iberoamericana.

FERNÁNDEZ RODRÍGUEZ, N. (2010). “El Auto de la conversión de santa Tais entre dos géneros: hacia los orígenes de la comedia hagiográfica" en Estudios sobre la Edad Media, el Renacimiento y la temprana Modernidad. (Eds. F. Bautista Pérez y J. Gamba Corradine). San Millán de la Cogolla, La Rioja: Instituto Biblioteca Hispánica del Cilengua : Sociedad de Estudios Medievales y Renacentistas : Seminario de Estudios Medievales y Renacentistas: 557-569. 
FERRER VALLS, T. (2012). "El drama bíblico a fines del XVI: La colección teatral del Conde de Gondomar y la anónima Comedia de la escala de Jacob" en La Biblia en el teatro español. (Ed. F. Domínguez Matito y J. A. Martínez Berbel). Vigo, Pontevedra: Academia del Hispanismo; San Millán de la Cogolla, La Rioja: Fundación San Millán de la Cogolla: 169-182.

FLECNIAKOSKA, J. L. (1961). La formation de la Auto religieux en Espagne adelante Calderón (1550-1635). Montpellier: Paul Déhan.

HUERTA VIÑAS, F. (ed.) (1976). Teatre bíblic. Barcelona: Barcino.

IGLESIA CATÓLICA. Missale romanum: ex decreto samosancti Concilii Tridentini restitutum Pii V Partificis Max. Iussu editum et Clementis VIII ac Urbani VIII...auctoritate recognitum; in quo omnia quae ab Innocentio X Noussime addita sunt, ab erreribusque summa diligentia expurgatum. Venetiis, apud Cieras, 1648.

MANSO PORTO, C. (1996). Don Diego Sarmiento, Conde de Gondomar (15671626). Erudito, mecenas y bibliófilo. Galicia: Xunta de Galicia.

MENÉNDEZ PELÁEZ, J. (2005). "Teatro e iglesia en el siglo XVI: de la Reforma católica a la Contrarreforma del Concilio de Trento". Criticón 94-95: 49-67.

MUÑOZ, H. (2010). "El silencio en la liturgia". Vida sobrenatural 670: 288-293.

OROZCO, E. (1983). "Sentido de continuidad espacial y desbordamiento expresivo en el teatro de Calderón. El soliloquio y el aparte", en Calderón. Actas del Congreso Internacional sobre Calderón y el teatro del Siglo de Oro (Madrid, 8-13 de junio de 1981). Madrid: CSIC, Vol. 1: 125-64.

RATZINGER, J. (1990). El Camino Pascual. Madrid: BAC Popular.

RESINES, L. (ed.) (1987). Catecismos de Astete y Ripalda. Madrid: Biblioteca de Autores Cristianos.

REYES PEÑA, M. (1988). El Códice de autos viejos. Un estudio de historia literaria. Sevilla: Alfar.

REYES PEÑA, M. (2003). "Vida y Martirio de Santa Bárbara, una comedia inédita de la colección teatral del conde de Gondomar”. Criticón 87-88-89: 745764.

ROMEU, J. (ed.) (1957). Teatre hagiogràfic. Barcelona: Barcino.

SÁNCHEZ LORA, J. L. (1988). Mujeres, conventos y reforma de la religiosidad barroca. Madrid: Fundación universitaria española.

STEINER, G. (2003). Lenguaje y silencio. Ensayos sobre la literatura, el lenguaje y lo inhumano. (Traducción de Miguel Ultorio). Barcelona: Gedisa.

TREBOLLE, J. (2007) "Se oye la voz de un silencio divino. El culto del templo de Jerusalén". Illu. Revista de Ciencias de la Religión 19: 223-238.

UBERSFELD, A. (1978). Lire le théâtre. Paris: Sociales. 
TIEMPO PARA HABLAR Y TIEMPO PARA CALLAR: USO Y FUNCIÓN DEL SILENCIO EN UN AUTO RELIGIOSO...

URDEIX DORDAL, J. (2012). "Silencio y celebración litúrgica". Phase 307: 5967.

WARDROPPER, B. W. (1967). Introducción al teatro religioso del Siglo de Oro. Salamanca: Anaya. 
